\title{
Study on the Effect of Different Modified Zeolite to Phosphorus Activation in Red Soil
}

\author{
Jing Shi'1,2, Naiming Zhang1,2*, Chenguang Zhang1,2, Boxian Wei1,2 \\ ${ }^{1}$ College of Resource and Environment, Yunnan Agricultural University, Kunming, China \\ ${ }^{2}$ Soil Fertilization and Pollution Remediation Engineering Laboratory of Yunnan Province, Kunming, China \\ Email: 383110966@qq.com, *zhangnaiming@sina.com
}

How to cite this paper: Shi, J., Zhang, N.M., Zhang, C.G. and Wei, B.X. (2016) Study on the Effect of Different Modified Zeolite to Phosphorus Activation in Red Soil. Journal of Environmental Protection, 7, 2036-2046.

http://dx.doi.org/10.4236/jep.2016.713158

Received: November 1, 2016

Accepted: December 16, 2016

Published: December 19, 2016

Copyright $\odot 2016$ by authors and Scientific Research Publishing Inc. This work is licensed under the Creative Commons Attribution International License (CC BY 4.0).

http://creativecommons.org/licenses/by/4.0/

\begin{abstract}
The activation of soil-fixed phosphorus is a long-term concern in soil science. In order to enhance the activation effect to soil-fixed phosphorus in red soil, different modified zeolite, through physical, chemical method and the associated both physics and chemistry, was used in this paper. The results showed as following: 1) the activated ability to soil-fixed phosphorus in red soil for modified zeolite was higher than the common one signally. Order of the ability for all kinds of modification zeolite in absolute activation amount and activation rate was: Modified in high temperature ammonium saturated zeolite $>$ Ammonium saturated zeolite $>$ Modified in high temperature zeolite $>$ Common zeolite. 2) The increasing rate of modified phosphorus in high temperature ammonium saturated zeolite and ammonium saturated zeolite had a decline trend with time postponed while that for modified phosphorus in high temperature zeolite and routine zeolite was rising gradually with time postponed. For ammonium saturated zeolite, the increasing rate of phosphorus in low available phosphorus content red soil was significantly faster than that in red soil with the higher content of available phosphorus. 3) The activation rate for the same modified zeolite showed difference in different phosphorus level soil. The order is: $\mathrm{SP}_{\text {high }}>\mathrm{SP}_{\text {medium }}>\mathrm{SP}_{\text {low }}$.
\end{abstract}

\section{Keywords}

Activation, Phosphorus, Red Soil, Zeolite

\section{Introduction}

Phosphorus is one of the necessary nutritional elements during plant growth and also a limiting factor of water eutrophication [1]. Red soil is the main arable soil in China and its phosphorus content is abundant, but the content of available phosphorus is 
generally low. Though the phosphorus needs for the crop can be met by using phosphorus fertilization but it is still not an effective way to solve the problem. For one reason, the seasonal crop utilization of phosphate is only $5 \%-10 \%$ [2] [3]. Besides, most of the available $\mathrm{P}$ will be fixed in the soil in the form of fixed phosphorus. For one thing, phosphorus fertilizer is overused in order to ensure the yield and food security. For another, there exist different levels of eutrophication in over $80 \%$ of lakes and reservoirs [4] [5] [6]. Phosphate application must be reduced in order to protect the environment and prevent the eutrophication. Meanwhile, phosphate mineral is nonrenewable resource. Considering these factors, to make full use of the fixed state of phosphorus in the soil, in order to balance food production, water environment protection and phosphate mineral resource, has become an inevitable choice. Therefore the research of cost-effective activation method of the soil fixed phosphorus is meaningful.

Studies showed that the accumulation of insoluble phosphate in the soil can be released by the zeolite and therefore as a source of supply of plant available phosphorus [7] [8] [9] [10]. However, the existed methods were not ideal to the activation effect on soil fixed phosphorus. In order to improve the effect of phosphorus activation using zeolite further, the physical method of high-temperature modification, saturated $\mathrm{NH}_{4}{ }^{+}$ chemical methods and high-temperature modification with saturated $\mathrm{NH}_{4}{ }^{+}$combination of physical and chemical methods were used in this research. Together with solubilizing simulation experiments in three phosphorus levels, it focused on finding the method that can be applied in fixed phosphorus activation of red soil.

\section{Materials and Methods}

\subsection{Tested Soil and Regional Profiles}

Soil samples used in this study were taken from Yunlong Reservoir farmland soil which is the largest urban centralized drinking water source of Kunming. Sampling depth was $5-20 \mathrm{~cm}$ topsoil. The soil samples were air-dried and ground through a sieve of $1 \mathrm{~mm}$ aperture and stored in a sealed bag for use. The basic properties of the soils are shown in Table 1.

\subsection{Design of Experiments}

\subsubsection{Experiment Materials}

Natural zeolite is an aluminum silicate mineral with basic metal frame shape. As it has

Table 1. Experimental soils' basic properties and contents of phosphorus.

\begin{tabular}{cccccc}
\hline Sample Numbers & Soil types & $\begin{array}{c}\text { Available phosphorus } \\
\left(\mathrm{mg} \cdot \mathrm{kg}^{-1}\right)\end{array}$ & $\begin{array}{c}\text { Total phosphorus } \\
\left(\mathrm{g} \cdot \mathrm{kg}^{-1}\right)\end{array}$ & $\begin{array}{c}\text { Organic matter } \\
\left(\mathrm{g} \cdot \mathrm{kg}^{-1}\right)\end{array}$ & $\mathrm{pH}$ \\
\hline $\mathrm{SP}_{\text {high }}$ & Red soil & 42.27 & 1.217 & 22.70 & 5.60 \\
$\mathrm{SP}_{\text {medium }}$ & Red soil & 22.45 & 0.985 & 34.47 & 5.75 \\
$\mathrm{SP}_{\text {low }}$ & Red soil & 9.07 & 1.023 & 23.82 & 5.83 \\
\hline
\end{tabular}


many internal cavities and channels, it is strong in cation exchange and selective adsorption performance, as well as its rich adsorption capacity. Zeolite used in this study collected from Yunnan and its main components are clinoptilolite. Cation exchange capacity is $89.3 \mathrm{cmol} / \mathrm{kg}$. Molecular formula is $\left(\mathrm{SiO}_{2}\right)\left(\mathrm{Al}_{2} \mathrm{O}_{3}\right)$. Its weight is 218.247 and chemical formula is $\left(\mathrm{CaNa}_{2}\right) \mathrm{Al}_{2} \mathrm{Si}_{7} \mathrm{O} \cdot 6 \mathrm{H}_{2} \mathrm{O}$.

\subsubsection{The Experimental Design}

This experiment set up 4 treatments with 3 replications. 4 treatments are: Treatment 1 was common zeolite treatment; Treatment 2 was high temperature modified zeolite; Treatment 3 was ammonium saturated zeolite and Treatment 4 was high-temperature modification of ammonium saturated zeolite. The proportion ratio of modified zeolite is 1:100 and three red soil samples with $\mathrm{SP}_{\text {high, }}$, the $\mathrm{SP}_{\text {medium }}$ and $\mathrm{SP}_{\text {low }}$ were added according to this ratio. Soil sample was taken every $10 \mathrm{~d}$ with a total of 4 times. The available phosphorus content was determined every time, the absolute amount of the activation of phosphorus was calculated by subtracting the available phosphorus content in CK treatment from the available phosphorus content of each zeolite activation treatment; the increasing rate of available phosphorus was calculated by dividing increasing amount of absolute available phosphorus by available phosphorus content in CK then multiplied by $100 \%$. By subtracting the increasing rate of previous available phosphorus from the last available phosphorus, calculating the dynamic increase rate of available Phosphorus, the activation rate of Phosphorus was calculated from dividing the increase rate of absolute available phosphorus by total phosphorus in CK soil then multiplied by $100 \%$.

\subsection{The Method of Determining Index}

Soil available phosphorus was measured by sodium bicarbonate extraction-molybdenum antimony anti-colorimetric determination method. Total phosphorus in soil use $\mathrm{NaOH}$-molten molybdenum, antimony anti-colorimetric determination method. $\mathrm{pH}$ value was tested by the precision $\mathrm{pH}$ meter with PHS-3C; the soil organic matter uses external heating potassium dichromate oxidation method for determination.

\section{Results and Discussion}

\subsection{Effect and Variance Analysis of Different Modification Zeolite to Activate Red Soil Phosphorus}

\subsubsection{Effect of Different Modification Zeolite to Activate Red Soil Phosphorus}

It showed that the absolute increment of available phosphorus with high-temperature modification of ammonium saturated zeolite was the highest between the four modified zeolites (Table 2). The absolute increments of available phosphorus were $23.48 \mathrm{mg} \cdot \mathrm{kg}^{-1}$, $15.10 \mathrm{mg} \cdot \mathrm{kg}^{-1}$ and $7.92 \mathrm{mg} \cdot \mathrm{kg}^{-1}$. Solubilizing effect of the ammonium saturated zeolite was also evident, the absolute increments of its available phosphorus were 20.30 $\mathrm{mg} \cdot \mathrm{kg}^{-1}, 12.35 \mathrm{mg} \cdot \mathrm{kg}^{-1}$ and $6.13 \mathrm{mg} \cdot \mathrm{kg}^{-1}$. Solubilizing effect of the high-temperature modified zeolite was better than the zeolite, and the absolute increments of its available phosphorus were $7.20 \mathrm{mg} \cdot \mathrm{kg}^{-1}, 6.90 \mathrm{mg} \cdot \mathrm{kg}^{-1}$ and $3.49 \mathrm{mg} \cdot \mathrm{kg}^{-1}$. The absolute increments 
Table 2. The absolute activation amount of different modification zeolite to activate red soil phosphorus.

\begin{tabular}{|c|c|c|c|}
\hline \multirow[b]{2}{*}{ Modification treatment } & $\mathrm{SP}_{\mathrm{h}}$ & $\mathrm{SP}_{\mathrm{m}}$ & $\mathrm{SP}_{1}$ \\
\hline & \multicolumn{3}{|c|}{$\begin{array}{c}\text { Absolute increments of } \\
\text { Available phosphorus }\left(\mathrm{mg} \cdot \mathrm{kg}^{-1}\right) \\
\text { (average } \pm \text { Standard deviation) }\end{array}$} \\
\hline Ordinary zeolite & $1.10 \pm 0.2 \mathrm{c}$ & $2.11 \pm 1.5 \mathrm{c}$ & $0.35 \pm 0.4 \mathrm{c}$ \\
\hline Modified zeolite in high temperature & $7.20 \pm 2.0 \mathrm{~b}$ & $6.90 \pm 2.6 \mathrm{~b}$ & $3.49 \pm 2.2 \mathrm{bc}$ \\
\hline Ammonium saturated zeolite & $20.30 \pm 3.1 \mathrm{a}$ & $12.35 \pm 2.6 \mathrm{a}$ & $6.13 \pm 3.2 \mathrm{ab}$ \\
\hline High temperature modified ammonium saturated zeolite & $23.48 \pm 1.6 \mathrm{a}$ & $15.10 \pm 2.9 \mathrm{a}$ & $7.92 \pm 4.1 \mathrm{a}$ \\
\hline
\end{tabular}

of ordinary zeolite were $1.10 \mathrm{mg} \cdot \mathrm{kg}^{-1}, 2.11 \mathrm{mg} \cdot \mathrm{kg}^{-1}$ and $0.35 \mathrm{mg} \cdot \mathrm{kg}^{-1}$. It follows that the ordinary zeolite could activate the fixed state phosphorus in the soil but its activation effect was not obvious.

Overall, the combination of Zeolite and saturated $\mathrm{NH}_{4}{ }^{+}$can significantly improve the solubilizing phosphorus amount of zeolite. The main reason is to add saturated $\mathrm{NH}_{4}^{+}$ can increase the cation exchange capacity of zeolite. So that the exchange absorption amount of zeolite to free state metal cations in the soil ( of $\mathrm{Fe}^{2+}$, of $\mathrm{Al}^{3+}$, of $\mathrm{Ca}^{2+}$ ) was effectively increased and the fixation to phosphate ion was reduced [11]. Meanwhile soluble phosphorus was released through the cation exchange interaction of $\mathrm{Ca}^{2+}$ from insoluble calcium phosphate [12]. The exchange capacity order of different absorption ion to $\mathrm{Ca}^{2+}$ was as follows [13]: $\mathrm{H}^{+}>\mathrm{Na}^{+}>$of $\mathrm{NH}_{4}^{+}>\mathrm{K}^{+}>\mathrm{Mg}^{2+}>\mathrm{Ba}^{2+}$. It follows that different cation has great difference in selective exchange to $\mathrm{Ca}^{2+}$. The main reason that the high temperature modified zeolite has better solubilizing phosphorus effect than ordinary zeolite is the adsorption in the zeolite voids with a certain amount of organic matter. The solubilizing effect of the zeolite is hindered by the relatively stable nature of organic matter, for there is no reaction with insoluble phosphate by the cation exchange role, and also the occupation of the organic matter to zeolite in adsorption capacity. High-temperature burning can effectively remove the organic matter adsorbed on the zeolite voids and thus increase the adsorption ability and adsorption capacity of the zeolite, and its phosphate solubilizing capacity will be significantly better than the zeolite without the high-temperature burning. The solubilizing effect of untreated zeolite is not obvious, it has the reasons: Firstly, the tested soil is red soil with strong acid, and this soil has secondary phosphorus fixation which make the secondary fixation of activated phosphate ion [14]; Secondly, low application amount of zeolite make its cation exchange and adsorption capacity relatively smaller, which is similar with the research result of $\mathrm{Li}[10]$.

\subsubsection{Variance of Different Modification Zeolite to Activate Red Soil Phosphorus}

It shows in Figure 1(a) that there was no significant difference between high-temperature modified of ammonium saturated zeolite and ammonium saturated zeolite in solubilizing phosphorus effect, but their solubilizing phosphorus effect was highly 


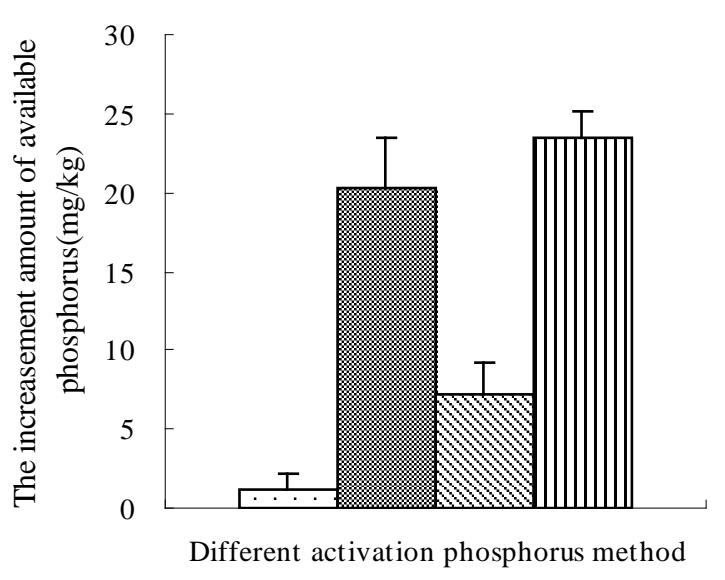

(a)

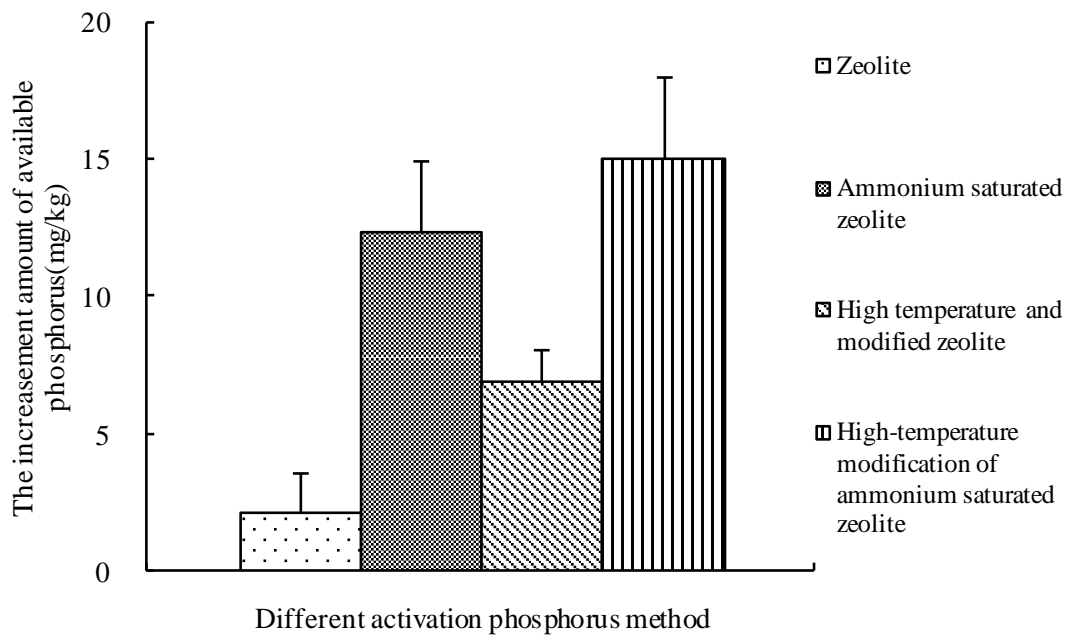

(b)

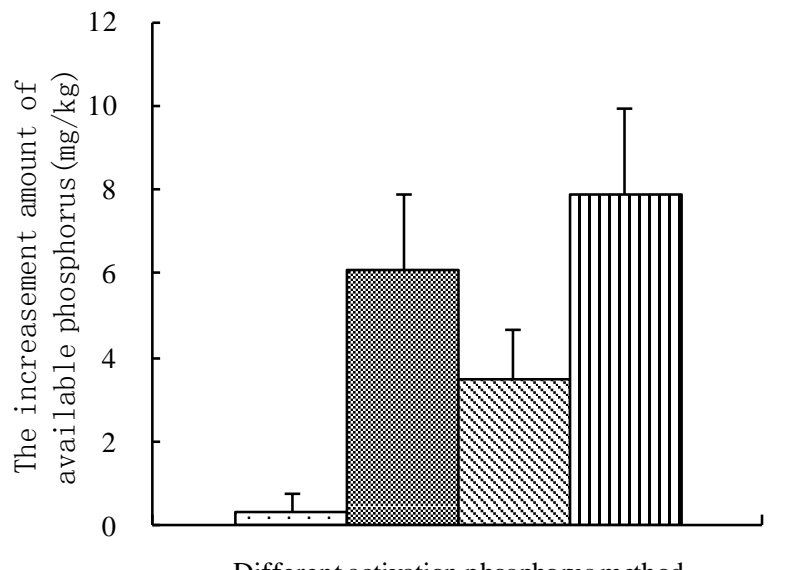

๑Zeolite

Ammonium saturated zeolite

High temperature and modified zeolite

ФHigh-temperature modification of ammonium saturated zeolite

Different activation phosphorus method

(c)

Figure 1. (a) The difference of (PS high) phosphorus activation effect in different modification treatment zeolite; (b) The difference of (PS medium) phosphorus activation effect in different modification treatment zeolite; (c) The difference of (PS low) phosphorus activation effect in different modification treatment zeolite. 
different with the high-temperature-modified zeolite; Solubilizing phosphorus effect of the high-temperature modified zeolite was also significantly different with ordinary zeolite. Regarding the red soil with high SP, the solubilizing effect order of zeolite from four different treatments are: high-temperature modified ammonium saturated zeolite $>$ ammonium saturated zeolite $>$ high temperature modified zeolite $>$ zeolite. Figure 1(b) shows that High-temperature modified ammonium saturated zeolite has no big difference with ammonium saturated zeolite about solubilizing effect; their solubilizing effects are highly different with high temperature modified zeolite. It also has significant difference between high-temperature modified zeolites and zeolite. The solubilizing effect of Zeolite for the red soil with medium level SP was: high temperature modification of ammonium saturated zeolite $>$ ammonium saturated zeolite $>$ high temperature modified zeolite $>$ zeolite. Figure 1(c) shows that there is no significant difference between high-temperature modified ammonium saturated zeolite and ammonium saturated zeolite, but it has no common with high temperature modified zeolite in solubilizing effect; The solubilizing effect of the ammonium saturated zeolite has no great difference with high temperature modified zeolite but different with Zeolite; The difference was not vital between high temperature modified zeolite and zeolite. The solubilizing effect order of four treatments with low SP red soil was: high-temperature modified ammonium saturated zeolite $>$ ammonium saturated zeolite $>$ high temperature modified zeolite $>$ zeolite.

\subsection{Influence of Different Modified Zeolite on the Dynamic Increasing Rate of Available Phosphorus in Red Soil}

It can be seen that in the same period, the increasing rates of available phosphorus in red soil are different for the zeolite with different treatments (Figures 2(a)-(c)). The dynamic increasing rate of available phosphorus from 3 soil samples in the $0-10 \mathrm{~d}$ period of high-temperature modified ammonium saturated zeolite were 19.61\%, 22.50\% and $26.53 \%$, which were higher than the other three periods. Within the $0-10 \mathrm{~d}$ of ammonium saturated zeolite, the dynamic increasing rate of available phosphorus from 3 soil samples were $17.17 \%, 18.06 \%$ and $30.34 \%$, which were significantly higher than the results from other three periods. And the dynamic increasing rate of available phosphorus with these two treated zeolite showed a descending trends. In addition, in the $0-10 \mathrm{~d}$ for high temperature modified zeolite, the dynamic increasing rate of available phosphorus from three soil samples was $2.35 \%, 3.54 \%$ and $5.15 \%$, which were lower than the results of other three periods, and their dynamic increasing rate of available phosphorus showed ascending trends. And the zeolite also has the similar pattern.

The reason that the dynamic increasing rate of available phosphorus from hightemperature modified ammonium saturated zeolite and ammonium saturated zeolite showing descending trends is that zeolite absorbed saturated $\mathrm{NH}_{4}^{+}$in extremely rich content, which enhance the cation exchange ability and amount of zeolite, and the activated phosphorus amount was also raised through cation exchange, but over time, 


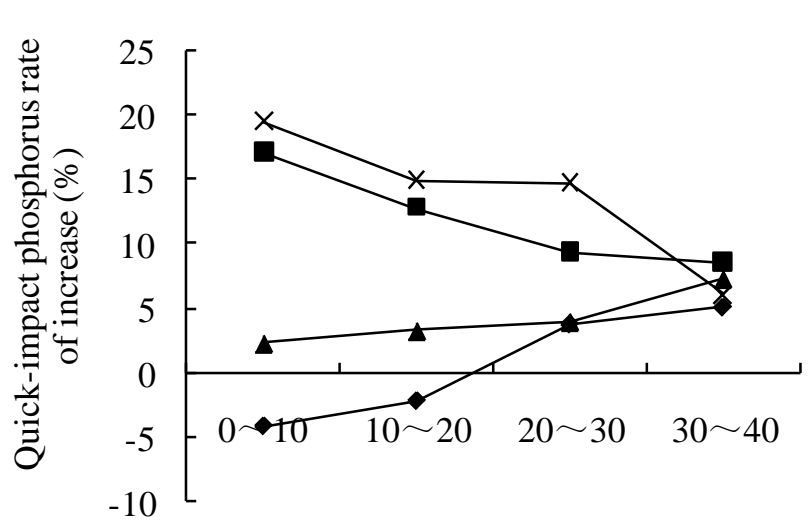

๑ Zeolite

Sampling time period(d)

(a)

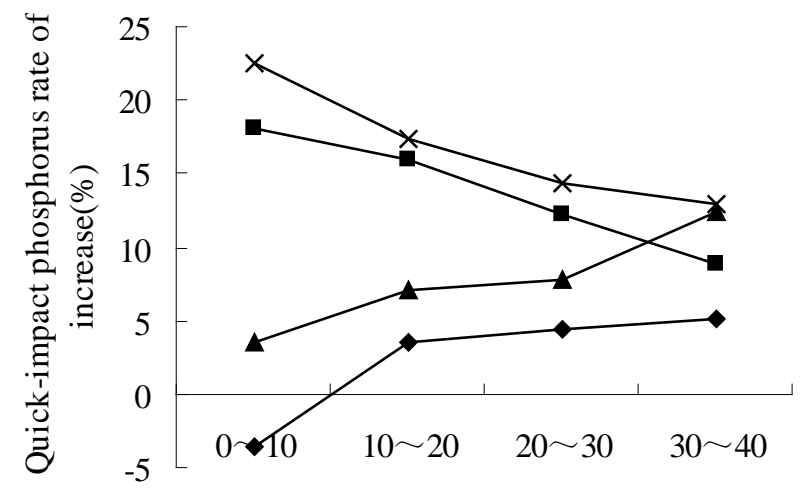

Sampling time period(d)

(b)

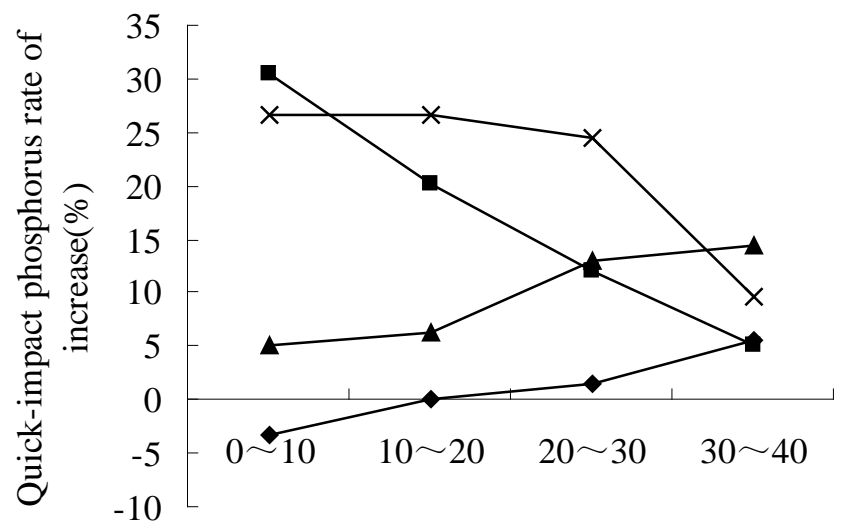

Sampling time period(d)

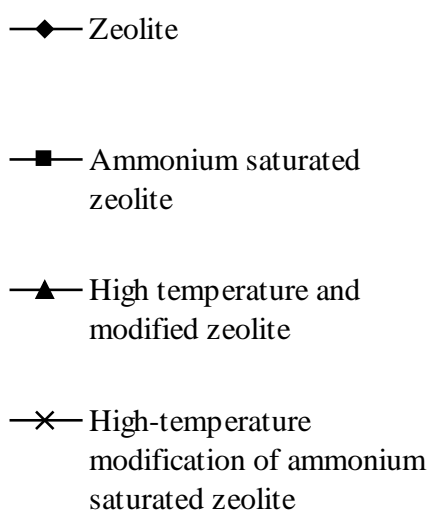

$\multimap$ Zeolite

$\rightarrow$ Ammonium saturated zeolite

$\smile \_$High temperature and modified zeolite
$\times$ High-temperature modification of ammonium saturated zeolite

(c)

Figure 2. (a) (PS high) dynamic increasing rate of phosphorus in different modification treatment zeolite; (b) (PS medium) dynamic increasing rate of phosphorus in different modification treatment zeolite; (c) (PS low) dynamic increasing rate of phosphorus in different modification treatment zeolite. 
gradually the saturated $\mathrm{NH}_{4}^{+}$was consumed and cation exchange amount was reduced, so that the dynamic increasing rate of available $\mathrm{P}$ was declined. The dynamic increasing rate of available phosphorus of high temperature modified zeolite and the ordinary zeolite showing ascending trends is because that their solubilizing mechanism was a slow reaction process, and at the beginning zeolite need to absorb the ions $\mathrm{K}^{+}$and $\mathrm{NH}^{4+}$ that has cation exchange ability in soil, then by cation exchanges to react with the metal cation of insoluble phosphorus in soil, the phosphate ion will be released slowly [15]. It is just as the existence of this time difference that there have been followed by an upward trend of the dynamic increasing rate of available phosphorus, and also precisely as this phenomenon, the zeolite cannot play the role of activating soil phosphorus and even make negative effect. This could be the reason in the early stage that zeolite showed negative value.

\subsection{Effect of Different Modified Zeolite on the Activation Rate of Phosphorus in Red Soil}

Figures 3(a)-(c) showed that the different treated zeolite has variable activation phosphorus rates to the same soil sample. The modified ammonium saturated zeolite has the highest activation rate of phosphorus, and the phosphorus activation rates in three soil samples with high SP, medium SP, and low SP are $1.93 \%, 1.53 \%$ and $0.77 \%$. It follows from that the phosphorus activated mode of high-temperature modified ammonium saturated zeolite has the best effect in high SP. It was seen in Figure 3(a) that there was no significant difference of phosphorus activation rate between high-temperature modified ammonium saturated zeolite and ammonium saturated zeolite, the difference are significant between ammonium saturated zeolite and high-temperature modified zeolite, and also between high temperature modified zeolite and ordinary zeolite. It was seen in Figure 3(b) that there was no significant difference of phosphorus activation rate between high-temperature modified ammonium saturated zeolite and ammonium saturated zeolite, and big difference between ammonium saturated zeolite and high-temperature modified zeolite, and also big difference between high temperature modified zeolite and ordinary zeolite. Figure $3(c)$ showed that high-temperature modified ammonium saturated zeolite had no difference with ammonium saturated zeolite, but it had vital difference with high temperature modified zeolite; Ammonium saturated zeolite had no difference with high temperature modified zeolite, but it had highly difference with ordinary zeolite; and also big difference between high temperature modified zeolite and ordinary zeolite.

As the different mechanisms of activating phosphorus between different processed zeolite, there was a big difference for phosphorus activation effect of the same soil. High-temperature modified ammonium saturated zeolite has the best activating phosphorus effect in the four processed zeolite because the soil organic matter absorbed in the zeolite voids was removed by high temperature, and the absorption capacity of zeolite was enlarged and cation exchange capacity of zeolite was also increased through combination with saturated $\mathrm{NH}_{4}^{+}$. This combined physical and chemical method can 


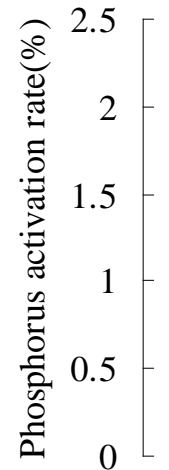

$\mathrm{C}$

\section{Different activation of} phosphorus

(a)
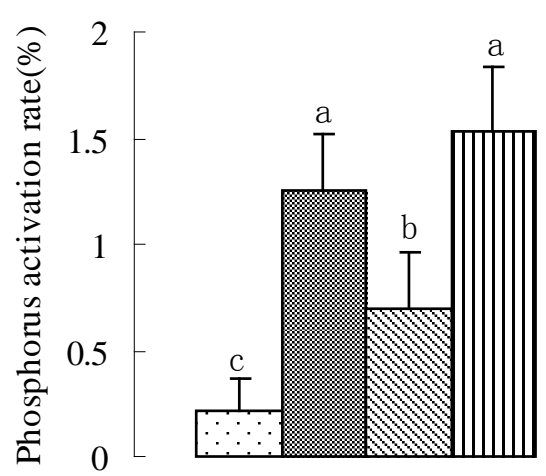

Different activation of phosphorus

(b) $\square$ Zeolite

Ammonium saturated zeolite

\$ High temperature and modified zeolite

ם High-temperature modification of ammonium saturated zeolite $\square$ Zeolite

Ammonium saturated zeolite

\$ High temperature and modified zeolite

\section{Ш High-temperature} modification of ammonium saturated zeolite

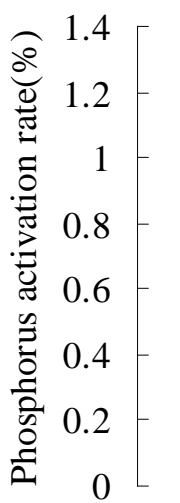

$\mathrm{C}$

\section{Different activation of phosphorus}

$\square$ Zeolite

Ammonium saturated zeolite

\$ High temperature and modified zeolite

凹 High-temp erature modification of ammonium saturated zeolite

(c)

Figure 3. (a) The difference between activation rate of phosphorus in different modification treatment zeolite (PS high); (b) The difference between activation rate of phosphorus in different modification treatment zeolite (PS medium); (c) The difference between activation rate of phosphorus in different modification treatment zeolite (PS low). 
mostly activate the fixed phosphorus in red soil. However, the phosphorus activation rate of high temperature modified ammonium saturated zeolite was quite different between three soil samples. The reasons are: firstly, total phosphorus content is different in these three soil samples. Secondly, available phosphorus content in the soil sample with high SP are the highest, which makes the free cation content that can fix available phosphorus relatively less, thus saturated $\mathrm{NH}_{4}{ }^{+}$absorbed on high temperature modified zeolite could have cation exchange reaction with metal cation in insoluble phosphate, and the activation rate of phosphorus can be maximized.

\section{Conclusions}

The ability of zeolite in activating phosphorus of the red soil with different modified treatment was significantly higher than the ordinary unmodified one, and the treatment with high temperature modified and saturated with ammonium ion has the highest phosphorus activation amount. The absolute amount of activating phosphorus with different treatments has the order as follows: high-temperature modified ammonium saturated zeolite $>$ ammonium saturated zeolite $>$ high-temperature modified zeolite $>$ ordinary zeolite.

For the tested soil samples with high, middle and low levels of rapid available phosphorus content, the increasing rate of soil phosphorus activation with different treatments has the same general trend. The increasing rate of modified phosphorus in high temperature ammonium saturated zeolite and ammonium saturated zeolite had a decline trend with time postponed while that for modified in high temperature zeolite and routine zeolite were rising gradually with time postponed. For ammonium saturated zeolite, the increasing rate of phosphorus in low available phosphorus content red soil was significantly faster than that in red soil with the higher content of available phosphorus. All these are related with their different activation mechanisms.

The four treatments by the usage in the soil with high, middle and low available phosphorus content have the same order of activation rate to phosphorus: high-temperature modified ammonium saturated zeolite $>$ ammonium saturated zeolite $>$ high temperature modified zeolite> ordinary zeolite, but the activation rate for the same modified zeolite showed difference in different phosphorus level soil. The order is: $\mathrm{SP}_{\text {high }}>\mathrm{SP}_{\text {medium }}>\mathrm{SP}_{\text {low }}$

\section{Acknowledgements}

Project supported by the science and technology innovation talent plan of Yunnan Province (No. 2015HC018); national water pollution prevention and treatment of major projects (No. 2012ZX07102-003).

\section{References}

[1] Schindler, D.W. (1997) The Evolution of Phosphorus Limitation in Lakes. Science, 195, 260-262. https://doi.org/10.1126/science.195.4275.260

[2] He, Z.L., Yuan, K.N. and Zhu, Z.X. (1990) The Effect of Organic Anions on Phosphate Ad- 
sorption. Acta Pedologica Sinica, 27, 377-383. (In Chinese)

[3] Sakaih, T. (1991) Secretion of Acid Phosphatase by the Roots of Several Crop Species under Phosphorus-Deficient Conditions. Soil Science and Plant Nutrition, 37, 129-140. https://doi.org/10.1080/00380768.1991.10415018

[4] Pomeioy, L.R., Simith, E.E. and Crant, C.M. (1965) The Exchange of Phosphorus between Estuarine Water and Sediments. Limnology and Oceanography, 10, 167-172. https://doi.org/10.4319/lo.1965.10.2.0167

[5] Zhang, Y., Zheng, B.H., Liu, H.L., et al. (2005) The Traits Analysis of Nitrogen and Phosphorus Nutrients after Gorges Reservoir Impounding. Water Resource Protection, 21, 2326. (In Chinese)

[6] Xu, D.X., Qin, Y.W. and Zhang, L. (2009) Phosphorus Forms and Its Distribution Characteristics in Sediments and Soils of Water Level Fluctuating Zone of the Backwater Reach from Input River of Three Gorges Reservoir. Environmental Science, 5, 83-90. (In Chinese)

[7] Barbarick, L., Lai, T.M. and Eberl, D.D. (1990) Exchange Fertilizer (Phosphate Rock Plus Ammonium-Zeolite) Effects on Sorghum-Sudangrass. Soil Science Society American Journal, 54, 911-916. https://doi.org/10.2136/sssaj1990.03615995005400030050x

[8] Ando, H. and Mihara, C. (1996) The Fate of Ammonium Nitrogen Applied to Flooded Rice as Affected by Zeolite Addition. Soil Science, 42, 531-538.

https://doi.org/10.1080/00380768.1996.10416322

[9] Li, L.J. (1995) Ammonia Saturated Zeolite Increased the Yield of the Effect and the Influence of the Fertilizer Utilization Ratio. Soils, 3, 147-150. (In Chinese)

[10] Li, L.J. and Zhang, L. (1996) Exchange Sex $\mathrm{NH}_{4}^{+}$-Zeolite to Improve Soil p Force Research. Soil Science Society of America Journal, 27, 139-140.

[11] Zorpas, A.A., Constantinides, T., Vlysside, A.G., et al. (2000) Heavy Metal Uptake by Natural Zeolite and Metals Partitioning in Sewage Sludge Compost. Bioresource Technology, 72, 113-119. https://doi.org/10.1016/S0960-8524(99)00110-8

[12] Guan, L.Z. and Li, H.Z. (1992) The Effect of Increase of Natural Zeolite and Nitrogen and Phosphorus Nutrients and Some Fertility Regulation Mechanism of Nature. Chinese Journal of Soil Science, 23, 205-208. (In Chinese)

[13] Li, L.J. and Yin, X. (1999) Ammonium Saturated Zeolite-Apatite Soil Phosphorus Release the Role and Application. International Chinese Agriculture Science and Technology Annual Meeting.

[14] Bogumil, K. and Barbara, G. (2010) Mechanochemical Activation of Phosphate Rock in Presence of Zeolites. Praemysl Chemiczny, 89, 414-418.

[15] Abd-Alla, M.H. (1994) Use of Organic Phosphorus by Rhizobium Leguminosarum Biovar Viceae Phosphatases. Biology and Fertility of Soils, 18, 216-218.

https://doi.org/10.1007/BF00647669 
Submit or recommend next manuscript to SCIRP and we will provide best service for you:

Accepting pre-submission inquiries through Email, Facebook, LinkedIn, Twitter, etc. A wide selection of journals (inclusive of 9 subjects, more than 200 journals)

Providing 24-hour high-quality service

User-friendly online submission system

Fair and swift peer-review system

Efficient typesetting and proofreading procedure

Display of the result of downloads and visits, as well as the number of cited articles

Maximum dissemination of your research work

Submit your manuscript at: http://papersubmission.scirp.org/

Or contact jep@scirp.org 